\title{
Diagnóstico e tratamento da hepatite B
}

\author{
Diagnosis and treatment of hepatitis B
}

\author{
Marcelo Simão Ferreira
}

Resumo A hepatite $B$ constitui grave problema de saúde pública. Estima-se que 350 milhões de pessoas, ou seja, $5 \%$ da população mundial sejam portadores dessa virose. Admite-se que a infecção evolui para a cura em $90 \%$ a $95 \%$ dos casos e para o estado de portador crônico nos restantes 5\% a 10\%; a infecção persistente pode resultar também em cirrose, insuficiência hepática e carcinoma hepatocelular. O diagnóstico de qualquer das formas clínicas da hepatite $B$ realizase através de técnicas sorológicas. Os médicos, hoje, possuem acesso a modernas técnicas laboratoriais capazes de avaliar a carga viral, o índice de replicação do agente infeccioso e a eficácia das novas medicações utilizadas. Vários agentes antivirais têm sido usados no tratamento dos indivíduos com hepatite crônica, como o intérferon alfa, a lamivudina, o famciclovir, e o adefovir dipivoxil, entre outros. A imunização ativa utilizando as modernas vacinas recombinantes constitui, na atualidade, a arma mais importante no combate à infecção pelo vírus da hepatite $B$.

Palavras-chaves: Hepatite viral. Hepatite B. Interferon. Lamivudina. Vacinas.

Abstract Hepatitis B constitutes a serious public health problem. It has been estimated that 350 million people - approximately $5 \%$ of the world population - have been infected by this virus. Of the people infected, in $90 \%$ to $95 \%$ of them there will be a spontaneous resolution of the disease. In $5 \%$ to $10 \%$ of the cases, though, the infection will persist and a chronic hepatitis will develop that may evolve leading, in the end, to liver cirrhosis, liver failure and/or carcinoma of the liver. The diagnosis of the different stages of the disease (i.e., acute, chronic infection) is performed using modern serologic techniques. Physicians, more recently, are having access to a series of laboratory tests which permit them to evaluate the viral load, replication of the virus and to testing of the efficacy of new anti-viral drugs. For the treatment of chronic hepatitis $B$ new agents have been tested and some are being used with different degrees of success, such as, alfa-interferon, lamivudine, famciclovir, and adefovir dipivoxil, among others. Active immunization, using modern recombinant vaccines, are lately, the most important instrument of control of the infection caused by the hepatitis $B$ virus.

Key-words: Hepatitis. Hepatitis B. Interferon. Lamivudine. Vaccine.

A hepatite $B$ continua sendo um dos mais importantes problemas de saúde pública em todo o mundo. Cerca de 350 milhões de pessoas, ou seja, $5 \%$ da população do planeta, são portadores dessa virose ${ }^{22}$. A maioria dos indivíduos infectados concentra-se em determinadas áreas geográficas, tais como, o Sudeste Asiático, a África Central e a região Amazônica, onde a prevalência de marcadores sorológicos do vírus
B (VHB) varia de $10 \%$ a $95 \% 22$. Um elevado percentual das pessoas que portam cronicamente esse patógeno não apresentam doença hepática ativa (portador são), mas a infecção persistente pode resultar também em cirrose, insuficiência hepática e carcinoma hepatocelular ${ }^{131}$ (Figura 1). Durante as últimas décadas, estudos clínicos e experimentais desenvolvidos em todo mundo expandiram os conhecimentos sobre a hepatite

Disciplina de Doenças Infecciosas e Parasitárias da Universidade Federal de Uberlândia, MG Endereço para correspondência: Dr. Marcelo Simão Ferreira. R. Goiás 480/500, 38400-027 Uberlândia, MG, Brasil. Telefax: 5534 236-3151.

Recebido para publicação em 19/5/2000 

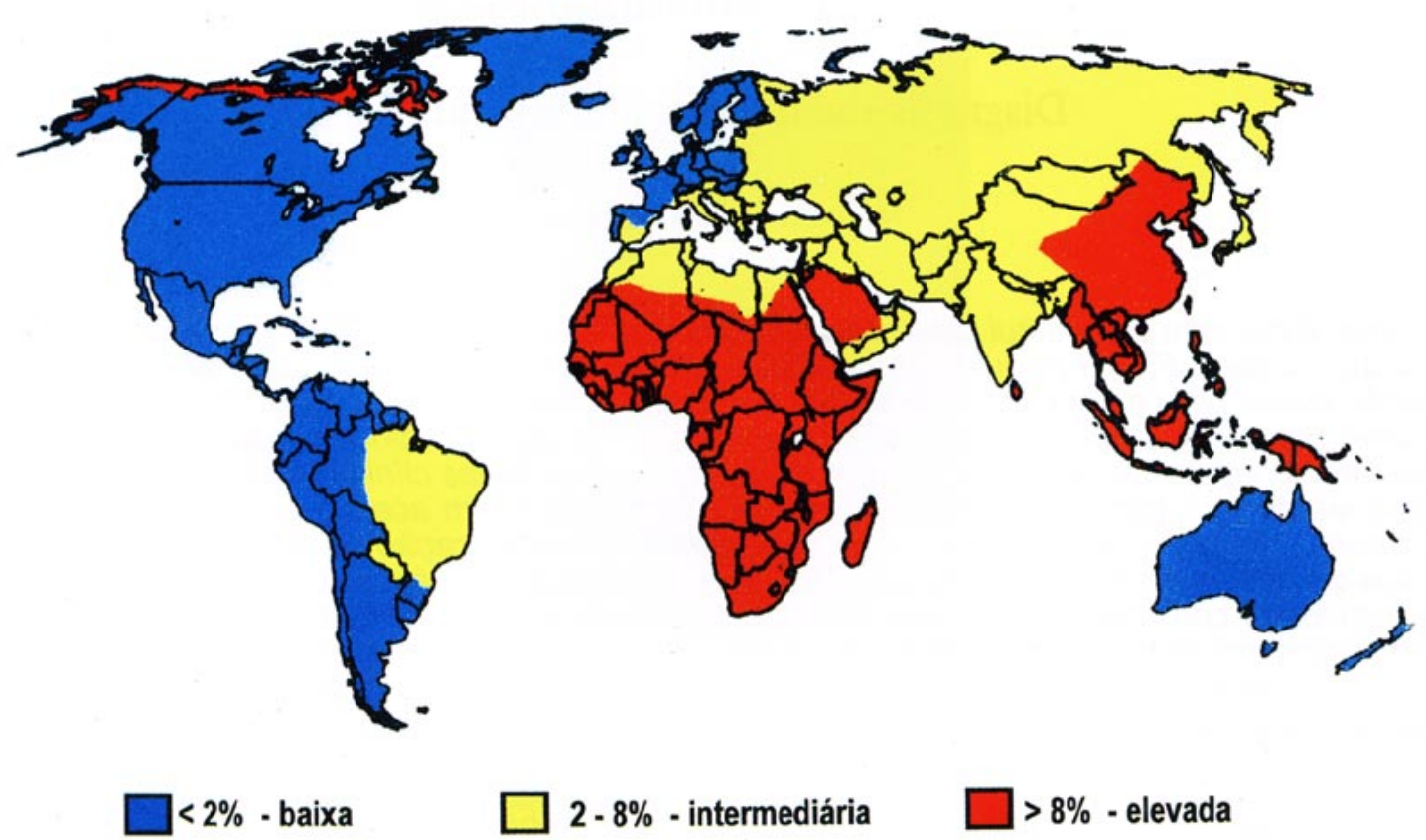

$2-8 \%$ - intermediária

$\square>8 \%$ - elevada

Figura 1 - Estimativa da prevalência de portadores (AgHBs+) do vírus da hepatite $B$ no mundo.

B em seus diferentes aspectos e, hoje, dispõemse de sofisticadas técnicas para o seu diagnóstico e de drogas sabidamente eficazes para o seu tratamento ${ }^{25}{ }^{31}$. A aplicação de técnicas de biologia molecular permitiu também notáveis avanços no conhecimento do próprio VHB e na demonstração da sua importância como fator etiológico de hepatopatias crônicas e do hepatocarcinoma ${ }^{25}$. A imunização ativa utilizando as modernas vacinas recombinantes constitui, na atualidade, a arma mais importante no combate a essa virose ${ }^{3738}$.

\section{HISTÓRIA NATURAL DA HEPATITE B}

A transmissão do $\mathrm{VHB}$ se faz fundamentalmente através das vias parenteral e sexual ${ }^{46}$. O rigoroso controle, hoje realizado, em grande parte dos bancos de sangue, praticamente eliminou de algumas áreas geográficas, a transmissão transfusional e na atualidade, a aquisição parenteral ocorre, com poucas exceções, apenas em viciados em drogas injetáveis, em inoculações acidentais com quantidades mínimas de sangue ou mais raramente, através da realização de acupuntura e tatuagens ${ }^{17}$. Em regiões de prevalência alta, a transmissão perinatal adquire grande importância, como ocorre, por exemplo, nos países do Sudeste Asiático e na África Equatorial. A presença do VHB no sêmen e nas secreções vaginais facilita a passagem de partículas infectantes através das superfícies mucosas, durante a relação sexual. $A$ hepatite $B$ pode ser considerada uma das mais importantes doenças sexualmente transmissíveis do homem ${ }^{46}$.

Certos grupos populacionais são considerados de alto risco para aquisição do VHB; entre eles, incluem-se, profissionais de saúde das áreas médico-odontológicas, hemodialisados, homossexuais masculinos, hemofílicos, prostitutas, toxicômanos, imunossuprimidos e deficientes mentais. A infecção também mostra-se altamente prevalente em familiares de portadores crônicos e em tribos indígenas da Região Amazônica ${ }^{1213}$.

O VHB pode causar doença hepática aguda e crônica. Após um período de incubação de cerca de 45 a 180 dias, os indivíduos infectados desenvolvem quadro de hepatite aguda, na maioria das vezes subclínica e anictérica. Apenas $20 \%$ evoluem com icterícia e em cerca de $0,2 \%$ dos pacientes, a doença assume caráter fulminante com alta letalidade ${ }^{38}$. Classicamente, admite-se que a infecção aguda pelo VHB evolui 
para a cura em $90 \%$ a $95 \%$ dos casos, e para o estado de portador crônico nos restantes $5 \%$ a $10 \%$. Metade desses portadores não apresentam doença hepática (portadores sãos), mas a outra metade mostra sinais de atividade inflamatória no fígado, de variada intensidade, por muitos anos, podendo desenvolver cirrose hepática e/ ou hepatocarcinoma nas fases mais tardias da enfermidade ${ }^{112942}$. Nos recém-nascidos de mães portadoras do VHB, a cronicidade da infecção é a regra e cerca de $98 \%$ das crianças persistem com marcadores sorológicos de infecção ativa pelo $\mathrm{VHB}$, durante várias décadas da vida ${ }^{42}$.

Nos pacientes com hepatite crônica B (definida sorologicamente como persistência do antígeno de superfície do VHB-AgHbs por mais de 6 meses) pode-se observar, durante a sua longa evolução, a presença de duas fases bem distintas e de duração variável ${ }^{43}$; na primeira, em geral, correspondendo à períodos mais precoces da doença, o VHB demonstra intensa replicação, comprovada pela presença no soro do AgHbs, do antígeno "e" (AgHbe), do próprio DNA viral (DNA-VHB), detectado por técnica de reação em cadeia da polimerase (PCR), além dos anticorpos contra o core viral (anti-Hbc) da classe IgG e, ocasionalmente, da classe IgM; a biópsia hepática nesses indivíduos mostra atividade inflamatória portal e periportal que pode variar de leve a intensa, na dependência do grau imunitário do indivíduo. O VHB, nessa fase, ainda não se encontra integrado ao genoma do hepatócito, existindo sob forma epissomal; a expressão de antígenos virais na membrana do hepatócito é abundante, facilitando a ação de linfócitos T citotóxicos. Esse período pode persistir por vários anos. Ao longo do tempo, entretanto, esses pacientes tendem a permanecer positivos para o anti-Hbe (15\% a $20 \%$ ao ano), indicando que o grau de replicação reduziu, trazendo como conseqüência a diminuição da reação inflamatória no fígado ${ }^{43}$. Vale salientar, contudo, que, a replicação viral não encontra-se totalmente abolida, uma vez que técnicas mais sensíveis (PCR) podem comprovar a presença do DNA viral no soro e tecido hepático ${ }^{32}$. Infelizmente, a soroconversão Hbe/anti-Hbe ocorre em fases avançadas da hepatopatia crônica em um substancial número de doentes, e os benefícios que dela advém pouco alteram o prognóstico desses indivíduos. A soroconversão $\mathrm{Hbe/anti-Hbe,} \mathrm{em} \mathrm{geral} \mathrm{é} \mathrm{precedida} \mathrm{por} \mathrm{elevação}$ abrupta das aminotransferases e exacerbação dos fenômenos histológicos de inflamação indicando que está havendo clareamento imune das partículas virais no fígado ${ }^{6}$; esse fenômeno pode ter intensidade variável, podendo adquirir carácter fulminante em alguns casos ${ }^{7}$. É possível que essa soroconversão se antecipe com o emprego de drogas tais como, intérferon e lamivudina, trazendo benefícios aos pacientes, antes que a doença evolua para a cirrose hepática ${ }^{32}$.

Nesse período de brusca elevação das aminotransferases torna-se necessário afastar a possibilidade de que outros agentes (drogas, vírus delta, A, C) possam estar exacerbando as lesões inflamatórias preexistentes no fígado.

Após a soroconversão, podem surgir fenômenos de reativação, caracterizados pelo reaparecimento dos marcadores de replicação e exacerbação das atividades bioquímica e histológica ${ }^{67}$. Essa reativação pode ocorrer de forma espontânea ou após o emprego de drogas imunossupressoras (corticóides, quimioterápicos antineoplásicos, etc), podendo adquirir carácter fulminante em alguns $\operatorname{casos}^{6}$. Diversos fatores podem modificar a história natural da infecção pelo VHB. Coinfecções com outros vírus como o vírus da imunodeficiência humana (VIH), vírus da hepatite $\mathrm{C}(\mathrm{VHC})$ e vírus da hepatite delta (VHD), alcoolismo crônico, uso concomitante de drogas hepatotóxicas e imunossupressão são condições que podem alterar o curso clínico da doença e/ ou exacerbar a replicação do $\mathrm{VHB}^{5}$; nos estados de imunossupressão, por exemplo, apesar do aumento da carga viral do hospedeiro, observase uma menor agressão do sistema imune aos hepatócitos infectados pelo vírus, resultando em níveis de aminotransferases séricos pouco expressivos e ausência de inflamação e fibrose à biópsia hepática; também, o percentual de portadores crônicos do vírus se torna maior após a infecção primária pelo VHB, devido à incapacidade desses indivíduos com déficit imunitário em clarear esse patógeno ${ }^{5}$.

Em determinadas regiões do mundo, como por exemplo, na região do Mediterrâneo, cepas mutantes do VHB podem infectar um percentual elevado dos portadores. A mutação mais conhecida é a que ocorre no segmento pré-core do genoma do VHB gerando um códon que indica parada de transcrição (stop codon). Nessa situação o AgHbe não é mais produzido, embora a replicação viral continue inalterada. A infecção humana por essa mutante parece associar-se a formas graves de hepatopatias, inclusive fulminantes ${ }^{39}$.

A cirrose hepática se instala progressivamente na hepatite crônica $B$, muitas vezes de forma 
oligo ou assintomática; a replicação pode estar presente nessa fase, embora seja mais freqüente o encontro do anti-Hbe ${ }^{42}$. Períodos de exacerbação da doença nesses doentes podem deteriorar substancialmente a função hepática remanescente ${ }^{11}$. O risco do surgimento de hepatocarcinoma é grande e os pacientes devem se submeter a um protocolo de vigilância a cada 3 ou 4 meses, com dosagem da alfafetoproteína sérica e realização de ultra-sonografia de alta resolução, objetivando detectar precocemente a presença de lesões neoplásicas de pequeno tamanho $(<2 \mathrm{~cm})$, passíveis de tratamento cirúrgico ou por alcoolização. Há evidências de que a terapia antiviral com intérferon pode prevenir o surgimento do hepatocarcinoma em pacientes com cirrose pelo $\mathrm{HBV}^{26}$.

\section{DIAGNÓSTICO DA HEPATITE B}

O diagnóstico de qualquer das formas clínicas da hepatite $B$ realiza-se através de técnicas sorológicas. Tais técnicas revelam-se fundamentais não apenas para o diagnóstico, mas também mostram-se muito úteis no seguimento da infecção viral, na avaliação do estado clínico do paciente e na monitorização da terapêutica específica $^{18}{ }^{19}$. As importantes descobertas realizadas nas áreas da virologia e da biologia molecular desses vírus, nos últimos anos, foram progressivamente sendo incorporados à rotina diária dos laboratórios de patologia clínica, permitindo aos médicos acesso às modernas técnicas capazes de avaliar a carga viral presente no indivíduo, o índice de replicação do agente infeccioso e a eficácia de novas medicações utilizadas no tratamento dessa virose ${ }^{25}$. Serão analisados de forma sumária, os padrões de resposta sorológica observados nas várias formas clínicas da hepatite $B$.

Hepatite aguda. A fase aguda da hepatite B caracteriza-se pela intensa replicação viral, que ocorre tanto nas formas sintomáticas, ictéricas da doença, quanto nas anictéricas e oligossintomáticas. O período de incubação varia de 2 a 6 meses. Cerca de 6 semanas após a contaminação, o AgHbs já encontra-se presente no soro, podendo permanecer positivo nos casos agudos por até 180 dias quando então desaparece e dá lugar ao surgimento do anticorpo anti-Hbs, algumas semanas ou meses depois, período esse denominado de janela imunológica. O surgimento do anticorpo anti-HBs indica sempre resolução do processo, conferindo imunidade duradoura à infecção pelo VHB. Cerca de $5 \%$ a $10 \%$ dos pacientes persistem com o $\mathrm{AgHbs}$ no soro além de 6 meses, tornando-se, portanto, portadores crônicos do vírus ${ }^{19}$. Nas Figuras 2 e 3 estão demonstrados os marcadores da hepatite B no sangue dos indivíduos com uma infecção primária típica com evolução para cura (Figura 2) e para hepatite crônica (Figura 3).

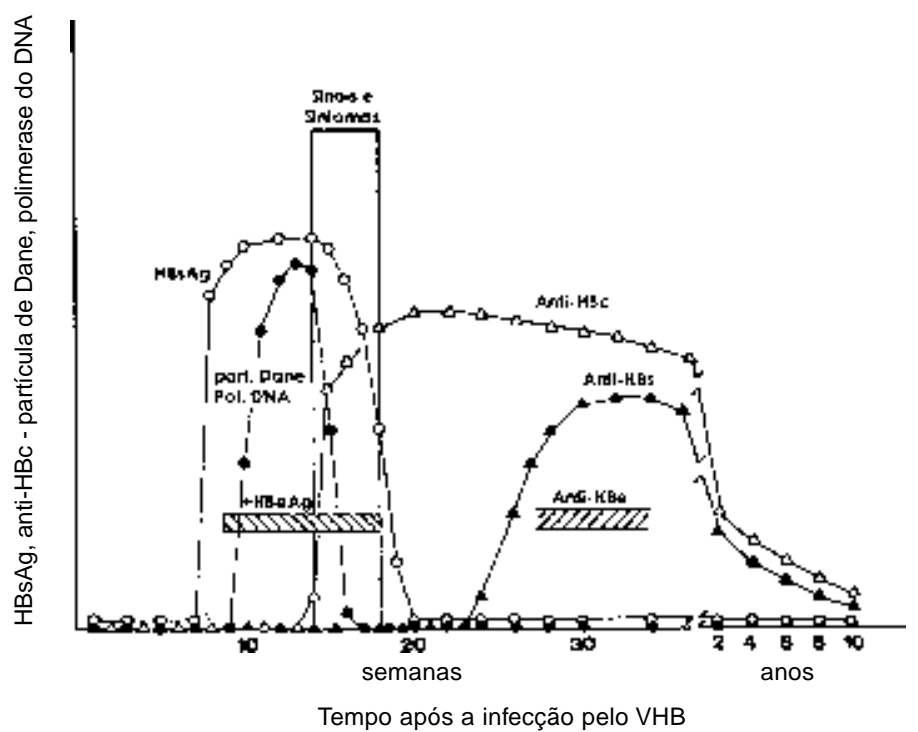

Figura 2 - Os marcadores da hepatite $B$ no sangue dos indivíduos com a infecção primária típica (positivos para o HBSAg) pelo vírus da hepatite B. 


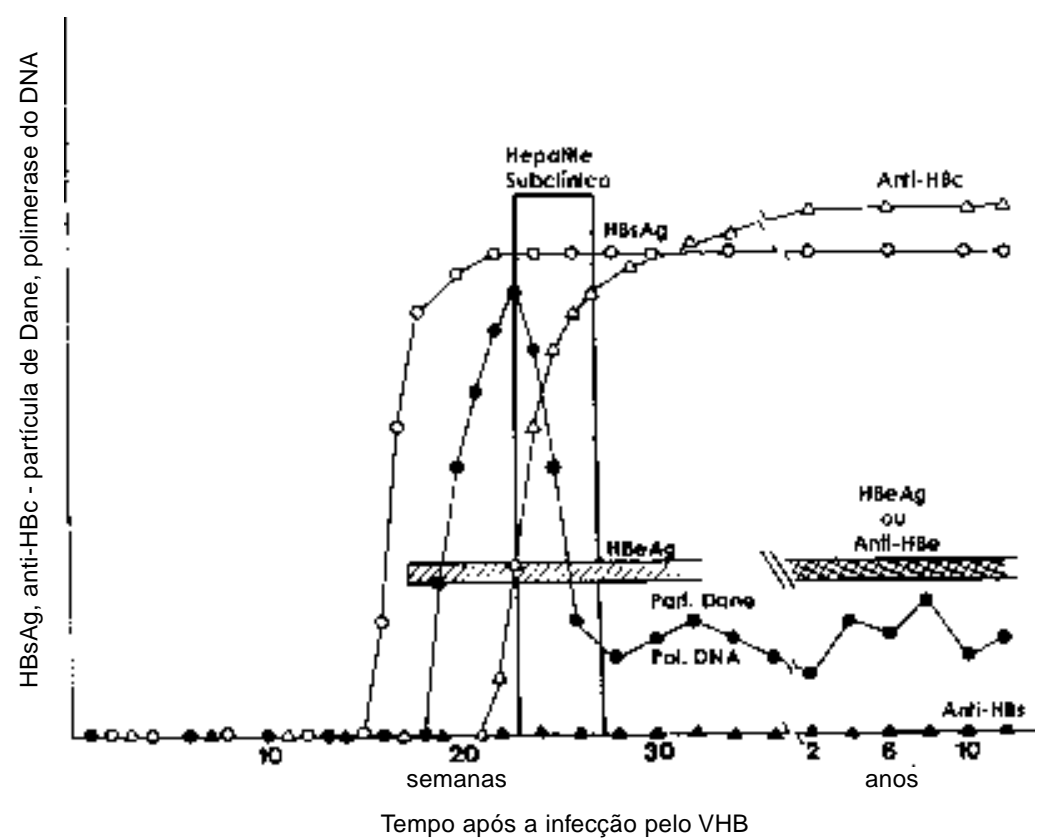

Figura 3 - Os marcadores da hepatite $B$ no sangue dos indivíduos com a infecção típica pelo vírus da hepatite $B$ que se torna persistente.

Durante o período de incubação detectamse, poucos dias após o surgimento do $\mathrm{AgHbs}$, anticorpos dirigidos contra $\mathrm{O} \mathrm{AgHbc}$ (antígeno core do vírus $B$ ); inicialmente surge a fração IgM (anti HbclgM), marcador considerado diagnóstico para a fase aguda da hepatite $B$, embora esteja presente também em alguns indivíduos com forma crônica da doença, particularmente nos períodos de reativação. $O$ anticorpo lgG contra - AgHbc também encontra-se presente na vigência da infecção aguda, quando aumenta progressivamente seus títulos no soro, permanecendo positivo em valores mais baixos, na maioria dos indivíduos, pelo resto da vida, mesmo após a cura da virose. $\mathrm{O}$ anti-HbclgG constitui o marcador clínico e epidemiológico mais importante da infecção pelo VHB. Detectase $\mathrm{o}$ antígeno $\mathrm{Hbe}(\mathrm{AgHbe})$ na fase inicial da infecção, pouco antes do surgimento do quadro clínico da doença aguda. Constitui um marcador indicativo de alta replicação viral. Sua duração nessa fase revela-se efêmera, desaparecendo em poucas semanas, dando lugar ao aparecimento do anti-Hbe. Sua persistência, além de 3 meses no sangue, pode indicar evolução para a cronicidade. Embora, obviamente estejam presentes na vigência da fase aguda, o DNA do
VHB e a atividade da DNA polimerase não são marcadores utilizados nessa fase. A detecção do $\mathrm{AgHbs}$, anti-Hbc (IgM e IgG) e AgHbe/anti-Hbe se faz na atualidade, utilizando-se técnicas imunoenzimáticas (ELISA) e, mais raramente, radioimunoensaio. Detecta-se o DNA-viral por PCR e a atividade da DNA polimerase, hoje pouco utilizada, através da incorporação de ATP marcado com $3 \mathrm{H}^{18192350}$.

Hepatite fulminante. Nas formas graves, fulminantes da hepatite $\mathrm{B}$, o AgHbs desaparece rapidamente, em geral, dentro de 4 semanas após o surgimento do quadro clínico. Nessa modalidade da doença, o diagnóstico baseia-se no encontro do anti HbclgM, que indica infecção aguda pelo VHB; o DNA viral mostra-se sempre presente na fase inicial do processo e deve ser solicitado rotineiramente nesses doentes. Se o indivíduo sobrevive ou é submetido ao transplante hepático, o anti-Hbs pode surgir precocemente, denotando resolução da virose ${ }^{1941}$.

Hepatite crônica. O perfil sorológico na hepatite crônica $B$ já foi praticamente discutido na história natural do VHB, descrita nessa revisão. Resta, como foi salientado, documentar nesses indivíduos se a replicação viral mostra- 
se [AgHbe(+); DNA-VHB(+)] ou não [anti Hbe (+); DNA-VHB (-)] presente. A demonstração da infecção pela mutante pré-core - anti Hbe (+); DNA-VHB (+) revela-se de grande importância na indicação terapêutica, uma vez que essa variante do vírus costuma responder mal à terapia com intérferon ${ }^{39}$. Co-infecções com outros vírus podem ser documentados sorologicamente; na associação com o vírus delta, o antidelta (anti$\mathrm{HD}$ ) total encontra-se presente, conjuntamente com o RNA do vírus detectado por PCR; na coinfecção com o vírus C, o anti-VHC (ELISA de $3^{a}$ geração), com confirmação da positividade do resultado pelo immunoblot (RIBA) ou PCR para detecção do RNA do VHC, constitui o método de eleição para o diagnóstico ${ }^{26}$. A biópsia hepática encontra a sua indicação na avaliação dos pacientes cronicamente infectados pelo VHB. Nela pode-se graduar a magnitude do processo inflamatório e da fibrose e ainda, através de técnicas de imunohistoquímica, documentar a presença de antígenos $S$ e Core do VHB no tecido. Também na co-infecção pelo vírus delta, a imunohistoquímica pode revelar o antígeno da hepatite delta $(\mathrm{AgHD})$ no núcleo dos hepatócitos.

Cirrose hepática. Na cirrose pelo VHB, pode haver ou não evidências de replicação viral. $A$ presença do AgHbe e do DNA-VHB deve ser utilizada para distinguir as duas formas. Nos casos com replicação, a atividade necroinflamatória revela-se maior e pode levar mais rapidamente à descompensação da doença. Como já mencionado, a maioria dos doentes cirróticos exibe a presença do anti-Hbe. A infecção pela mutante pré-core parece condicionar a uma evolução mais rápida para cirrose hepática e portanto deve ser detectada precocemente ${ }^{26}$.

Hepatocarcinoma. Nos hepatocarcinomas relacionados ao $\mathrm{VHB}$, o AgHbs e o anti-Hbc encontram-se, em geral, presentes no soro, embora em alguns pacientes, o AgHbs sérico possa apresentar-se negativo ou em baixos títulos, porém, mantendo-se a positividade do anti Hbc. A integração do DNA viral ao DNA do hospedeiro parece ser o evento inicial, que induz alterações celulares e no genoma do VHB, gerando processos de mutagênese e carcinogênese. As seqüências do DNA do VHB podem ser identificadas por PCR em tecidos tumorais de pacientes AgHbs negativos, mas com anti-Hbc, e, mesmo, anti-Hbs séricos positivos.

Portador são crônico do VHB. Portadores sãos do VHB mostram, em geral, a presença do
$\mathrm{AgHbs}$ no soro por mais de 6 meses e dosagens das aminotransferases séricas persistentemente normais. Em geral, não há sintoma ou sinal relacionado à infecção crônica viral relatado pelo paciente. Os marcadores de replicação do VHB podem estar presentes embora a maioria dos casos demonstra ser $\mathrm{HbeAg}$ negativo e anti-Hbe positivo. Quando biopsiados, a histologia hepática não revela sinais de atividade inflamatória na grande maioria dos casos. Não há indicação de terapia antiviral para esses indivíduos, pois raramente apresentam resposta às medicações $(<10 \%)$, devido a imunotolerância secundária à exposição precoce ao vírus ${ }^{20} 26$.

\section{TERAPIA DA HEPATITE B}

Nenhuma forma de tratamento específico encontra-se indicada nas formas agudas sintomáticas da hepatite B. Como já referido, cerca de $95 \%$ dos pacientes evoluem para a cura espontânea da infecção com aparecimento de anticorpos anti-Hbs, indicativos da resolução do processo. Aproximadamente, 2 a 3 pacientes por 1.000 infectados desenvolvem hepatite fulminante a subfulminante, formas com elevada mortalidade (> $80 \%$ ) e que necessitam ser tratadas em unidades de terapia intensiva, devido às múltiplas complicações decorrentes da insuficiência hepática aguda ${ }^{26}$. A melhor forma de tratamento desses doentes é através do transplante hepático, que tem sido realizado em vários centros do mundo, com grande sucesso. Em algumas casuísticas, a sobrevida após cinco anos de transplante nesses pacientes encontrase em torno de $80 \%$. A recorrência da infecção, nesses casos, revela-se improvável, uma vez que a replicação cessa rapidamente, inclusive com desaparecimento do $\mathrm{AgHbs}$ e surgimento precoce do anti-Hbs ${ }^{1941}$.

O grande contingente de indivíduos infectados pelo VHB com indicações para tratamento específico é representado principalmente pelos doentes com hepatite crônica e cirrose hepática. Muitas drogas têm sido avaliadas no tratamento dessa virose nos últimos 10 anos, e a eficácia de cada uma delas em estudos controlados apresenta resultados bastante variáveis. O principal objetivo no tratamento da infecção crônica pelo HBV é o de suprimir a replicação viral antes que ocorra dano irreversível ao fígado. Detalhadamente, podemos dividir os objetivos a serem alcançados com a terapêutica antiviral em três tópicos ${ }^{33}$ 34: a) supressão 
sustentada da replicação do VHB que pode ser demonstrada por: (1) DNA-VHB indetectável no soro (PCR-aninhado negativo); (2) soroconversão HbeAg/anti-Hbe; (3) soroconversão HbsAg/antiHbs; b) remissão total ou parcial da doença hepática: (1) normalização das aminotransferases séricas; (2) supressão da atividade necroinflamatória à biópsia hepática; c) diminuição do risco de desenvolvimento tardio de cirrose hepática e hepatocarcinoma, com conseqüente aumento da sobrevida.

O intérferon $\alpha$ (IFN $\alpha)$ foi a primeira droga aprovada para tratamento da infecção crônica pelo VHB. O IFN $\alpha$ possui atividade antiviral e imunomoduladora e ambas as ações mostramse importantes no tratamento dessa virose. Realizou-se a maioria dos estudos clínicos com essa medicação, embora o IFN $\beta$, que possui efeito antiviral predominante, também seja ativo. A terapia com IFN $\alpha$ deve ser considerada em pacientes com hepatite crônica $B$, com evidências de replicação viral (HbeAg e VHB-DNA positivos) e doença hepática ativa, (aminotranferases elevadas e atividade necroinflamatória à biópsia do fígado) ${ }^{31}{ }^{32}$. Os cirróticos compensados com evidências de replicação viral, devem também ser considerados candidatos ao tratamento. Ao contrário, hepatopatas crônicos com icterícia, ascite ou sinais de encefalopatia não devem ser tratados com IFN $\alpha$, devido ao risco de desencadeamento de insuficiência hepática e de infecções bacterianas graves. A dose comumente administrada de IFN $\alpha$ para pacientes com hepatite crônica $B$ é de 5 milhões de unidades diárias ou 10 milhões de unidades três vezes por semana, por via subcutânea, durante 4 a 8 meses $^{213132}$.

Uma metanálise dos estudos controlados, randomizados, mostrou que, essa citocina é benéfica para esses indivíduos e observou-se uma diferença significativa entre pacientes tratados e controles, quando avaliados após 6-
12 meses de seguimento pós-tratamento; o clareamento do HbeAg ocorreu em $33 \%$ dos tratados, comparado com $12 \%$ dos não tratados; o VHB-DNA desapareceu em $37 \%$ dos tratados e em $17 \%$ dos não tratados; e o $\mathrm{AgHbs}$ em $8 \%$ dos que receberam a droga contra $1,8 \%$ dos que não a receberam ${ }^{49}$. Os pacientes que responderam à medicação desenvolveram anti-Hbe, normalizaram as aminotransferases e mostraram sensível diminuição da atividade inflamatória à biópsia hepática ${ }^{49}$. Cerca de $70 \%$ dos doentes que se beneficiaram com o tratamento, mostraram exacerbação da atividade necroinflamatória hepática precedendo a soroconversão; aumentos, por vezes consideráveis das aminotransferases séricas foram documentados nesse período. Esse fato, provavelmente decorre de uma lise imunomediada dos hepatócitos infectados, ressaltando-se, entretanto, que, em pacientes cirróticos, esses fenômenos de reativação enzimática podem precipitar a descompensação clínica 263649 . Em alguns indivíduos, a soroconversão Hbe/anti-Hbe, pode ocorrer tardiamente, cerca de 3 a 6 meses, após o término da terapia. A vasta maioria (80-90\%) dos respondedores costuma manter a resposta à terapia muitos meses depois de tratados ${ }^{30}$. $\mathrm{A}$ erradicação completa da infecção pelo VHB tem sido raramente documentada, embora um clareamento tardio do AgHbs encontra-se reportado em $25 \%$ a $65 \%$ dos respondedores após vários anos de seguimento 26303340 . Os pacientes que não responderam a um primeiro curso de tratamento $\operatorname{com}$ IFN $\alpha$, podem ser retratados com o mesmo esquema terapêutico durante 6 meses; um estudo recente mostrou que um terço desses doentes apresentaram remissão da doença após o novo tratamento ${ }^{3}$.

Vários fatores têm sido identificados como preditivos de boa resposta ao tratamento com IFNa ${ }^{30} 343649$. Na Tabela 1, alinham-se alguns fatores preditivos.

Tabela 1 - Fatores preditivos de resposta favorável ao tratamento da hepatite B crônica com interferon a.
a) altos níveis de aminotransferases (> 100UI) séricos pré-tratamento
b) baixos níveis do DNA-VHB, pré-tratamento, no soro $(<200 \mathrm{pg} / \mathrm{ml})$
c) sexo feminino
d) histologia hepática com atividade necroinflamatória moderada a grave
e) infecção pelo VHB adquirida na fase adulta
f) ausência de co-infecções com outros vírus (VIH, VHC, VHD)
g) comportamento heterossexual. 
A resposta ao tratamento da infecção crônica pelo VHB com IFN $\alpha$ não se mostra uniforme em todos os grupos de doentes infectados. Naqueles que são AgHbe (+) e DNA-VHB (+), mas com aminotransferases normais a resposta à terapia revela-se ruim $(<10 \%)$, provavelmente, porque há tolerância imunológica ao microorganismo, secundária à exposição precoce (neonatal) ao $\mathrm{VHB}^{34}$. Nos portadores da mutante pré-core - Hbe $(-)$, anti Hbe (+), DNA-VHB (+) - com aminotransferases elevadas, o tratamento com IFN $\alpha$ mostra-se eficaz inicialmente, mas as recidivas tornam-se muito comuns após a suspensão da medicação². Às vezes esses indivíduos se beneficiem com uma duração maior da terapia (18 a 24 meses) ${ }^{21}$. A eficácia e a tolerância ao tratamento com IFN $\alpha$ em crianças com infecção pelo VHB replicativa revelaram-se similares às observadas em adultos ${ }^{36}$.

Vários efeitos adversos encontram-se associados ao uso prolongado do IFN $\alpha$; os mais comuns são os relacionados à chamada síndrome flu-like, em que febre, mialgias, mal estar e cefaléia estão presentes. Outros efeitos colaterais incluem perda de peso, alopécia, distúrbios neuropsiquiátricos (incluindo depressão profunda e suicídio) e queda no número de leucócitos e plaquetas. Os portadores de afecções autoimunes não devem fazer uso dessa medicação, devido ao risco de exacerbação da doença durante a terapêutica ${ }^{21} 303649$.

Diversos medicamentos têm sido, recentemente, utilizados no tratamento da infecção crônica pelo VHB. A descoberta de que esse vírus utiliza a enzima transcriptase reversa no seu ciclo de replicação celular, motivou vários autores a empregar medicações inibidoras dessa enzima, habitualmente indicadas para o tratamento da infecção pelo HIV, na terapêutica da hepatite crônica B. A lamivudina (3-thiacytidina - 3TC), um análogo de nucleosídeo, de potente ação contra a transcriptase reversa, mostrou ser a droga mais promissora desse grupo no tratamento da hepatite $B^{81024}$. Ela inibe a síntese do DNA-VHB, a partir do RNA pré-genômico, bloqueando portanto a síntese de novas partículas virais. Na maioria dos estudos até agora realizados, a dose utilizada foi de $100 \mathrm{mg}$ diária, por via oral, por no mínimo 12 meses. A droga mostrou-se bem tolerada e produziu rápido decréscimo dos níveis do DNA-VHB no soro que persistiu durante toda terapia, mas após o seu término houve reaparecimento do ácido nucléico viral em níveis similares aos observados antes do tratamento ${ }^{810}$. A soroconversão Hbe/anti-Hbe ocorreu em $15 \%$ a $20 \%$ dos pacientes tratados, percentuais esses similares aos documentados após um curso de 4 meses de monoterapia com IFN $\alpha$. Constatou-se a melhora bioquímica e histológica em aproximadamente $50 \%$ dos doentes, incluindo alguns que não haviam alcançado a soroconversão. A progressão da fibrose hepática foi retardada significativamente em todos os indivíduos tratados com lamivudina comparados com o placebo, independentemente da resposta sorológica $^{81024}$.

O alto índice de recidivas observado após o término da terapêutica com lamivudina pode estar relacionado à persistência do DNA-VHB circular (cccDNA) no núcleo do hepatócito ${ }^{31}{ }^{32}$. Esses ácidos nucléicos servem de molde para transcrição do RNA pré-genômico. A maioria dos antivirais ativos sobre o VHB possui pouco ou nenhum efeito sobre o DNA-VHB circular do núcleo hepatocítico, e isso parece ser a causa do rápido reaparecimento do ácido nucleico viral no soro após o término da terapia. Teoricamente, o clareamento viral poderia ser alcançado se as drogas fossem utilizadas por tempo prolongado, até que se esgotasse o pool do cccDNA, cuja meiavida revela-se muito longa e, o seu desaparecimento parece ser dependente da eliminação progressiva dos hepatócitos infectados ${ }^{31}{ }^{32}$. Um estudo recente demonstrou que o prolongamento da terapia com lamivudina para 18 meses levou à perda do $\mathrm{AgHbe}$ em $38 \%$, desaparecimento do DNA-VHB em $100 \%$ dos casos, além de normalização das aminotransferases séricas em 43\% dos pacientes tratados; a perda do $\mathrm{AgHbe}$ manteve-se sustentada após a retirada da droga, o que sugere que a medicação possa ser suspensa após o desaparecimento desse marcador sorológico?.

A lamivudina também encontra-se indicada na terapia de pacientes portadores de hepatite crônica pela mutante pré-core do VHB. Como esses indivíduos não possuem AgHbe, o objetivo final da terapêutica recai sobre o desaparecimento do DNA-VHB, além da melhora bioquímica e histológica. Dois estudos demonstraram a eficácia virológica, bioquímica e histológica dessa droga nesses pacientes, comparada ao placebo, embora em um deles o índice de recidiva pós terapêutico tenha sido elevado ${ }^{27} 4447$.

Os pacientes com cirrose hepática pelo VHB, em fase replicativa, também demonstraram 
melhora significativa nos seus parâmetros bioquímicos e virológicos, quando tratados com a lamivudina. A evolução e a sobrevida nesses casos aparentemente foram melhores nos doentes submetidos à terapêutica com esse antiviral $^{81027313248 \text {. }}$

Ao contrário do IFN $\alpha$, poucas variáveis tem demonstrado valor preditivo na resposta ao tratamento com lamivudina. Um trabalho conduzido no Sudeste Asiático demonstrou que altos níveis de alanina aminotransferase préterapia constituem fortes determinantes para a soroconversão Hbe/anti-Hbe durante a terapia e esse parâmetro, portanto, deve ser considerado na seleção dos pacientes que irão ser tratados. Os níveis de DNA-VHB séricos e a presença de fibrose à biópsia correlacionaram-se menos com a perda do AgHbe nesse estudo 4 .

A eficácia da lamivudina no tratamento de pacientes que não responderam à terapêutica com IFN $\alpha$ foi recentemente avaliado em estudo multicêntrico que envolveu 238 pacientes. Nesse trabalho, avaliou-se também se a terapia combinada (IFN $\alpha$ + lamivudina) era mais eficaz do que a droga utilizada isoladamente. $\mathrm{Na}$ monoterapia com lamivudina $(100 \mathrm{mg}$, VO, por 1 ano) observou-se soroconversão $\mathrm{Hbe}$ antiHbe em $18 \%$, normalização das aminotransferases em $44 \%$ e melhora histológica em $52 \%$ dos casos tratados; curiosamente, a combinação de drogas IFN $\alpha$ e lamivudina por 16 semanas, não mostrou eficácia superior à da monoterapia (soroconversão: $12 \%$; aminotransferases normais: $18 \%$ e melhora histológica: $32 \%)^{1645}$. Novos estudos mostram-se necessários para avaliar o efeito da combinação de drogas no tratamento da hepatite $B$.

O maior problema resultante do tratamento prolongado com lamivudina é o desenvolvimento de resistência por mutação na polimerase do VHB. A mais importante delas resulta em uma substituição de metionina por valina ou isoleucina no locus YMDD da molécula de DNA-polimerase. Essa substituição de aminoácidos confere resistência de magnitude de cerca de 10.000 vezes, sugerindo que a resposta antiviral não pode ser restabelecida aumentando-se a dose da medicação. A incidência dessa mutação tem sido reportada em cerca de $15 \%$ a $25 \%$ dos pacientes tratados por um ano e de $40 \%$ nos que receberam a droga por dois anos. $O$ índice de mutações parece ser maior e mais precoce nos pacientes portadores do HIV, uma vez que praticamente $100 \%$ deles desenvolvem mutantes após 3-4 meses de tratamento. O desenvolvimento de resistência deve ser suspeitado quando, durante o período de administração da droga, o DNA-VHB reaparece e as aminotransferases voltam a se elevar. Raras vezes, hepatite grave ou descompensação da cirrose hepática já foram documentadas em indivíduos que desenvolveram mutações $^{28}$. Em algumas publicações, os efeitos benéficos da administração continuada de lamivudina em pacientes que já desenvolveram mutações foram demonstrados e esse fato provavelmente deve-se à baixa capacidade de replicação das cepas mutantes. A retirada da medicação leva ao rápido desaparecimento dessas cepas e ao ressurgimento da cepa primitiva, existente antes do tratamento ${ }^{8} 10283132$.

Poucos efeitos colaterais têm sido observados durante a terapia com lamivudina, mesmo quando administrada em doses maiores $(300 \mathrm{mg} /$ dia). A diarréia pode eventualmente surgir durante o uso da medicação. A redução da dose mostrou-se necessária em pacientes com insuficiência renal (clearence de creatinina $<50 \mathrm{ml} /$ minuto) 810273132 .

Outros agentes antivirais já foram empregados no tratamento da hepatite crônica B. O famciclovir, um análogo de nucleosídeo, muito utilizado na terapêutica de infecções herpéticas, mostrou-se muito ativo em inibir a replicação do VHB, embora seu efeito sobre os níveis do DNA-VHB tenha sido menos potente e de caráter transitório. Sua ação, entretanto, já foi comprovada em doentes com cirrose hepática descompensada e na hepatite $B$ recidivante após o transplante hepático. A dose regularmente empregada é de $500 \mathrm{mg}$, por via oral, a cada 8 horas durante 4 a 6 meses. As mutantes resistentes já foram identificadas em pacientes submetidos a longos cursos de tratamento. Essas mutantes podem demonstrar resistência cruzada com a lamivudina. Menos de $2 \%$ dos pacientes tratados mostram efeitos colaterais ao famciclovir; entre os mais comuns, citam-se as náuseas, a dor abdominal, a diarréia, a cefaléia, a fadiga e a sonolência ${ }^{35}$.

Outros análogos de nucleosídeos encontramse em avaliação no tratamento da hepatite crônica B. O adefovir dipivoxil, em estudos preliminares, mostrou-se potente inibidor da replicação do VHB, reduzindo significativamente os níveis de DNA-VHB séricos e promovendo soroconversão Hbe/anti-Hbe em larga proporção dos pacientes tratados. Existem evidências da 
ação dessa droga em cepas do VHB mutantes resistentes à lamivudina ${ }^{14}$.

Novas abordagens terapêuticas têm sido ensaiadas na terapia da hepatite crônica B. Moléculas anti-sense ou ribozymes que impedem a transcrição do DNA-VHB e do RNA-VHB, interleucina 2, interleucina 12 , intérferon gama, levamisol, timosina e terapêutica imunomoduladora utilizando vacinas (vacinas de DNA, vacinas de células $T$ ) já foram utilizados em trabalhos controlados ou em casos isolados de hepatite crônica $B$, com resultados promissores, mas estudos adicionais mostram-se necessários para determinar o verdadeiro papel dessas abordagens na infecção crônica pelo VHB ${ }^{15}$.

Infelizmente, muitos pacientes infectados com - VHB, evoluirão com ou sem tratamento, para a cirrose hepática e o hepatocarcinoma. Os cirróticos descompensados, com icterícia, ascite e encefalopatia hepática, possuem poucas chances de resposta a qualquer terapia antiviral e, portanto, devem ser encaminhados para o transplante hepático. O maior problema observado nos transplantados VHB positivos é a reinfecção do enxerto com desenvolvimento de hepatite crônica, que pode ser grave em alguns casos, levando o paciente ao óbito ${ }^{31}$. Essa forma de doença hepática no transplantado é chamada de hepatite colestática fibrosante e parece depender de injúria hepatocítica decorrente de efeito citopático do vírus, quando a carga viral encontrase muito alta. O famciclovir e a lamivudina têm sido utilizados com algum sucesso para tratar as recorrências do VHB em pacientes submetidos à transplante ${ }^{3148}$. Essas drogas podem inclusive prevenir a reinfecção do fígado se forem administradas, pelo menos um mês antes do transplante e por, no mínimo, um ano após a cirurgia. Altas doses de imunoglobulina anti-hepatite $B$ também têm sido usadas para prevenir a reinfecção, mas infelizmente, alguns estudos demonstraram que esses anticorpos retardam, mas não evitam a infecção posterior do enxerto.

A Tabela 2 resume as principais estratégias hoje utilizadas no tratamento da infecção crônica pelo VHB.

Tabela 2 - Estratégias utilizadas no tratamento da infecção crônica pelo vírus da hepatite $B$.

\begin{tabular}{|c|c|c|c|c|c|}
\hline $\mathrm{AgHbs}$ & $\mathrm{AgHbe/anti} \mathrm{Hbe}$ & DNA-VHB & ALT/AST & Histologia & Conduta \\
\hline \multirow[t]{2}{*}{+} & \multirow[t]{2}{*}{$+/-$} & \multirow[t]{2}{*}{+} & \multirow[t]{2}{*}{ normais } & \multirow[t]{2}{*}{ normal } & IFN $\alpha$ ineficaz; lamivudina pode ser benéfica? \\
\hline & & & & & Vigilância para hepatocarcinoma necessária. \\
\hline+ & $-1+$ & - & normais & normal & expectante; vigilância para hepatocarcinoma necessária. \\
\hline+ & $+/-$ & + & elevadas & $\mathrm{HC}$ & IFN $\alpha$ por 4 a 8 meses; lamivudina por 1 ano (mínimo) \\
\hline+ & $-1+$ & + & elevadas & $\mathrm{HC}$ & $\begin{array}{l}\text { IFN } \alpha \text { ou lamivudina; elevado índice de recidivas. } \\
\text { (mutante pré-core) }\end{array}$ \\
\hline \multirow[t]{2}{*}{+} & \multirow[t]{2}{*}{$+/-$} & \multirow[t]{2}{*}{+} & \multirow[t]{2}{*}{ elevadas } & cirrose & Lamivudina; vigilância para \\
\hline & & & & compensada & hepatocarcinoma; duração da terapia desconhecida \\
\hline \multirow[t]{2}{*}{+} & \multirow[t]{2}{*}{$+/-/-/+$} & \multirow[t]{2}{*}{$+/-$} & \multirow{2}{*}{$\begin{array}{l}\text { normais ou } \\
\text { elevadas }\end{array}$} & cirrose & Lamivudina nos AgHbe/DNA positivos(?); \\
\hline & & & & descompensada & vigilância para hepatocarcinoma; transplante hepático. \\
\hline
\end{tabular}

$\mathrm{VHB}=$ vírus da hepatite $\mathrm{B} ; \mathrm{HC}$ + hepatite crônica; ALT/AST + aminotransferases; IFN $\alpha$ - intérferon $\alpha$

\section{REFERÊNCIAS BIBLIOGRÁFICAS}

1. Beasley RP. Hepatitis B virus: the major etiology for hepatocellular carcinoma. Cancer 61:1942-1956, 1988

2. Brunetto MR, Oliveri F, Columbatto P, Capalbo M, Barbera C, Bonino F. Treatment of chronic anti-Hbe-positive hepatitis B with interferon-alpha. Journal of Hepatology 22:42-44, 1995.

3. Carreño V, Marcellin P, Hadziyannis S, Salmerón J, Diago M, Kitis GE, Vafiadis I, Schalm SW, Zahm F, Manzarbeitia F, Jiménez FJ, Quiroga JA; Retreatment of chronic hepatitis $B$ e antigen-positive patients with recombinant interferon alfa 2a. Hepatology 30:277-282, 1999.
4. Chien RN, Lian YF, Atkins M. For Asian Hepatitis Lamivudine Trial Group. Pretherapy alanine transaminase level as a determinant for hepatitis $B$ e antigen seroconversion during lamivudine therapy in patients with chronic hepatitis B. Hepatology 30:770-774, 1999.

5. Colin JF, Cazals-Hatem D, Loriot MA, Martinot-Peignoux, Phan BN, Auperin A, Degott C, Benhamou JP, Erlingers, Valla $D$, Marcellin P. Influence of human immunodeficienty virus infection on chronic hepatitis $B$ in homossexual men. Hepatology 29:1306-1310, 1999. 
6. Davis GL, Hoofnagle JH. Reactivation of chronic type B hepatitis presenting as acute viral hepatitis. Annals of Internal Medicine 102:762-765, 1985.

7. Davis GL, Hoofnagle JH, Waggoner JG. Spontaneous reactivation of chronic hepatitis $B$ virus infection. Gastroenterology 86:230-235, 1984.

8. Dienstag JL, Perrilo RP, Schiff ER, Bartholomew M, Vicary C, Rubin M. A preliminary trial of lamivudine for chronic hepatitis B infection. The New England Journal of Medicine 333:1657-1661, 1995.

9. Dienstag JL, Schiff ER, Mitchell M, Casey Jr DE, Githin N, Lissoos T, Gelb LD, Condreay L, Crowther L, Rubin M, Brown N. Extended lamivudine retreatment for chronic hepatitis B: maintenance of viral supression after discontinuation of therapy. Hepatology 30:1082-1087, 1999.

10. Dienstag JL, Schiff ER, Wright TL, Perrilo RP, Hann HWL, Goodman Z, Crowther L, Condreay LD, Woessner M, Rubin M, Brown NA and US Lamivudine Investigator group. Lamivudine as initial treatment for chronic hepatitis $B$ in the United States. The New England Journal of Medicine 341:1256-1263, 1999.

11. Di Marco V, Lo lacono $O$, Camnà $C$, Vaccaro $A$, Guinta M, Martorana G, Fuschi P, Almasio PL, Craxi A. The longterm course of chronic hepatitis B. Hepatology 30:257264, 1999.

12. Gayotto LCC. Soroepidemiologia da hepatite pelo vírus B: experiência brasileira. Revista Paulista de Medicina 103:219-221, 1985.

13. Gayotto LCC, Quarentei AA, Cabral GL. Soroepidemologia das hepatites A e B nas regiões dos rios Biá e Alto Juruá, Amazonas Ocidental. Gastroenterologia e Endoscopia 3:106-116, 1984.

14. Gilson RJC, Chopra KB, Newell Am, Murray-Lyon IM, Nelson MR, Rice SJ, Tedder RS, Toole J, Jaffe HS, Weller IVD. A placebo-controlled phase I/II study of adefovir dipivoxil in patients with chronic hepatitis $B$ virus infection. Journal of Viral Hepatitis 6:387-395, 1999.

15. Heathcote J, McHutchison J, Lee S, Tong M, Benner K, Minuk G, Wright T, Fikers J, Livinst on B, Sette A, Chestnut and the CY-1899T Cell Vaccine study group. A Pilot study of the CY-1899T-Cell vaccine in subjects chronically infected with Hepatitis B. Hepatology 30:531-536, 1995.

16. Heathcote J, Schalm SW, Cianciara J, Farrel G, Feinman V, Shemann M. Lamivudine and intron A combination treatment in patients with chronic hepatitis $B$ infection (abstract). Journal of Hepatology 29(supl 1):43, 1998.

17. Hoofnagle JH. Chronic type B hepatitis. Gastroenterology 84:422-424, 1983.

18. Hoofnagle JH. Serodiagnosis of acute viral hepatitis. Hepatology 3:267-268, 1983.

19. Hoofnagle JH, Di Bisceglie AM. Serologic diagnosis of acute and chronic viral hepatitis. Seminars of Liver Disease. 11:73-83, 1991.
20. Hoofnagle JH, Shafritz DA, Popper H. Chronic type B hepatitis and the healthy HbsAg carrier state. Hepatology 7:758-763, 1987.

21. Janssen HLA, Gerken G, Carreño V, Marcellin $P$, Naoumov NV, Craxi A, Ring-Larsen H, Kitis G, Hattum JV, De Vries RA, Michielsen PP, Kate FJW, Hop WCJ, Heijtink RA, Honkoop P, Schalm SW. Interferon alfa for chronic hepatitis B infection: Increased efticacy of prolonged treatment. Hepatology 30:238-243, 1999.

22. Kane M. Global programme for control of hepatites $B$ infection. Vaccine 13(supl 1):547, 1995.

23. Kiyasu PK, Caldwell JH. Diagnosis and treatment of the major hepatotropic viruses. American Journal of Medical Sciences 306:248-261, 1993.

24. Lai CL, Chien RN, Leung NW, Chang TT, Quan R, Tai DI. A one year trial of lamivudine for chronic hepatitis B. Asia Hepatitis Lamivudine study group. New England Journal of Medicine 339:61-68, 1998.

25. Lau JY, Wright TI. Molecular virology and patogenesis of hepatitis B. Lancet 342:1336-1338, 1993.

26. Lee WM. Hepatitis B virus infection. New England Journal of Medicine 337:1733-1745, 1997.

27. Liaw YF. Current trends in therapy for chronic viral hepatitis. Journal Gastroenterology and Hepatology 12:346-353, 1997.

28. Liaw YF, Chien RN, Yeh CT, Tsai SL, Che CM. Acute exacerbation and hepatitis $B$ virus clearence after emergence of YMDD motif mutation during lamivudine therapy. Hepatology 30:567-572, 1999.

29. Liaw YF, Tai DI, Chu CM, Chen TJ. The development of cirrhosis in patients with chronic type B hepatitis: a prospective study. Hepatology 8:493-496, 1988.

30. Lin SM, Sheen IS, Chien RN, Chu CM, Liaw YF. Longterm beneficial effect of interferon therapy in patients with chronic hepatitis B virus infection. Hepatology 29:971975, 1999.

31. Lok ASK. Treatment of chronic hepatitis B. Journal of Viral Hepatitis 1:105-124, 1994.

32. Lok ASK. Hepatitis B infection: pathogenesis and management. Journal of Hepatology 32:89-97,2000.

33. Lok AS, Chung HT, Liu VW, Ma OC. Long-term follow-up of chronic hepatitis $B$ patients treated with interferon alpha. Gastroenterology 105:1833-1838, 1993.

34. Lok AS, Lai CL, Wu PC, Lau JY, Leung EK, Wong LS. Treatment of chronic hepatitis B with interferon: experience in Asian patients. Seminars in Liver Diseases 9:249-253, 1989.

35. Main J, Brown JL, Howells C. A double blind, placebocontrolled study of the effect of famciclovir on virus replication in patients with chronic hepatitis $B$ virus infection. Journal of Viral Hepatitis 3:211, 1996.

36. Malik AH, Lee WM. Hepatitis B Therapy: the plot thickens. Hepatology 30:579-581, 1999. 
37. Margolis HS, Alter MJ, Hadler SC. Hepatitis B: evolving epidemiology and implications for control. Seminars of Liver Diseases. 11:84-92,1991.

38. Mylley AG, Silverstein MDD, Dienstag JL. Indications for use hepatitis $B$ vaccine based on cost-effectiveness analysis. New England Journal of Medicine 307:644$652,1982$.

39. Naoumov NV, Schneider R, Groetzinger T, Jung MC, Miskas S, Pape GR. Precore mutant hepatitis B virus infection and liver disease. Gastroenterology 102:538543, 1992.

40. Niederau C, Heintgers T, Lange S, Goldman G, Neederau $\mathrm{CM}$, Mohr L. Long-term follow-up of HbeAg positive patients treated with interferon alpha for chronic hepatitis B New England Journal of Medicine. 334:1422-1427, 1996.

41. O' Grady JG, Alexander GJ, Hayllar KM, Willians R. Early indicators of prognosis in fulminant hepatic failure. Gastroenterology 97:439-445, 1989.

42. Perrilo RP, Aach RD. The clinical course and chronic sequelae of hepatitis $B$ virus infection. Seminars of Liver Disease 1:15-25, 1981.

43. Realdi G, Alberti A, Rugge M, Bortolotti F, Gigoli AM, Tremolada F. Seroconversion from hepatitis $B$ e antigen to anti-Hbe in chronic hepatitis B virus infection. Gastroenterology 86:230-235, 1984.

44. Santantonio T, Mazzola M, lacovazzi T, Miglietta A, Guastadisegni A, Pastore G. Long-term follow-up of patients with auti-Hbe/HB.V-DNA-positive chronic hepatitis $B$ treated for 12 months with lamivudine. Journal of Hepatology 32:300-306, 2000.

45. Schiff E, Karayalcin S, Grimm I. A placebo controlled study of lamivudine and interferon alpha $2 \mathrm{a}$ in patients with chronic hepatitis $B$ who previously failed interferon therapy. Hepatology 28:388A, 1998.

46. Szmuness W, Nuch MI, Prince AM. On the role of sexual behavior in the spread of hepatitis B infection. Annals of Internal Medicine 83:489-495, 1975.

47. Tassopoulos NC, Volpes R, Pastore G, Heathcote J, Buti M, Goldin RD, Hawley S, Baber J, Condreay L, Gray DF. The Lamivudine precore mutant study group. Efficacy of Lamivudine in patients with hepatitis $B$ e antigen-negative / hepatitis B virus DNA-positive (precore mutant) chronic hepatitis B. Hepatology 29:889-896, 1999.

48. Villeneuve JP, Condreay LD, Willens B, PomierLayrargues G, Fenyvers D, Bilodeau M, Ledua R, Peltekian K, Wong F, Margulies M, Heathcote EJ. Lamivudine treatment for decompensated cirrhosis resulting from chronic hepatitis B. Hepatology 31:207210, 2000.

49. Wong DK, Cheung AM, O'Rourke K, Naylor CD, Detsky AS, Heathcote J. Effect of alpha interferon treatment in patients with hepatitis B. A meta-analysis. Annals of Internal Medicine. 119, 312-323, 1993.

50. Zaaijer H, TerBorg F, Cuypers H, Hermus M, Lelie P. Comparison of methods for detection of hepatitis $B$ virus DNA. Journal of Clinical Microbiology 32:2088-2091, 1994. 